\title{
Anticoagulation therapy and hand surgery: Do we worry too much?
}

Sir,

Prophylactic anticoagulant therapies in the form of warfarin, clopidogrel or aspirin are commonly prescribed for patients who are at risk of thromboembolism. Examples of such patients include those with mechanical heart valves, chronic atrial fibrillation, a past history of venous thromboembolism and those thought to be at cardiac risk. Such patients requiring surgery can pose a challenge, as one has to weigh the risk of bleeding-related complications against the elevated risks of a potentially fatal thrombotic episode occurring should anticoagulants be halted for surgery. Despite existing literature exemplifying a low risk of peri-operative bleeding in dental, eye, joint, endoscopic procedures ${ }^{[1]}$ and authors advocating no interruption of the anti-thrombotic therapy in such surgeries (provided patients' international normalized ratio [INR] are within normal therapeutic range), there still exist no clear guidelines or data to define this risk in hand surgery. ${ }^{[2]}$ Anecdotally, it is still common practice in many units to stop anticoagulation therapy prior to hand surgery based mainly on surgeon preference. Wallace et al. ${ }^{[3]}$ have described that they, as early as 1996, had been performing hand surgeries without altering the patient's anticoagulant regimen, as long as the INR was $<3$. Retrospective analysis of all his patients who underwent surgery from 1996 to 2003 portrayed that there were no additional days of stay related to bleeding complications. In the same year, Smit and Hooper ${ }^{[2]}$ arrived at a similar conclusion after reviewing the records of their patients who underwent surgery either for carpal tunnel release or Dupuytren's contracture. Of the 852 procedures carried out, 22 patients were found to be on warfarin and despite not stopping or altering therapy, no peri or post-operative bleeding was reported. More recently, two prospective studies concurred that the continuation of anticoagulation for hand surgery is safe..$^{[4,5]}$ As described by Nandoe Tewarie and Bartels, of 
the 52 patients (out of 364) on anticoagulants, only one patient, who was on aspirin developed postoperative subcutaneous bleeding. ${ }^{[4]}$ Similarly, in the second study, of the 107 patients who were on anticoagulants, only one patient on clopidogrel developed a haematoma ${ }^{[5]}$. Admittedly, some of these studies are retrospective in nature. However, they do show that it is likely not necessary to stop anticoagulation prior to hand surgery (as long as INR is within therapeutic range in the case of Warfarin). Furthermore, with the lack of clear guidelines from the British Society for Surgery of the Hand, the surgeon is often left to weigh up the risks of peri- or postoperative bleeding against a potentially life-threatening thrombotic event. It is suggested that a randomised control trial or more adequately powered prospective study be conducted to determine the risk of peri- or postoperative bleeding as a result of anticoagulant therapy and to formulate definitive guidelines relating to this subject. However, it would also seem that the current evidence suggests that anticoagulant therapy need not be halted on a routine basis for such surgeries.

\section{Financial support and sponsorship}

Nil.

\section{Conflicts of interest}

There are no conflicts of interest.

\section{Mark Twoon ${ }^{1,2}$, Marc-James Hallam ${ }^{2}$}

${ }^{1}$ School of Medicine, University of Aberdeen, Scotland, 2Plastic, Reconstructive \& Aesthetic Surgery Unit, Aberdeen Royal Infirmary, Aberdeen, UK

Address for correspondence: Mr. Mark Twoon, Suttie Centre, Foresterhill Campus, University of Aberdeen, Aberdeen, AB25 2ZD, United Kingdom. E-mail: mark.twoon.11@aberdeen.ac.uk

\section{REFERENCES}

1. Dunn AS, Turpie AG. Perioperative management of patients receiving oral anticoagulants: A systematic review. Arch Intern Med 2003;163:901-8.

2. Smit A, Hooper G. Elective hand surgery in patients taking warfarin. J Hand Surg Br 2004;29:206-7.

3. Wallace $\mathrm{DL}$, Latimer MD, Belcher HJ. Stopping warfarin therapy is unnecessary for hand surgery. J Hand Surg $\mathrm{Br}$ 2004;29:203-5

4. Nandoe Tewarie RD, Bartels RH. The perioperative use of oral anticoagulants during surgical procedures for carpal tunnel syndrome. A preliminary study. Acta Neurochir (Wien) 2010;152:1211-3.

5. Edmunds I, Avakian Z. Hand surgery on anticoagulated patients: A prospective study of 121 operations. Hand Surg 2010;15:109-13.
This is an open access article distributed under the terms of the Creative Commons Attribution-NonCommercial-ShareAlike 3.0 License, which allows others to remix, tweak, and build upon the work non-commercially, as long as the author is credited and the new creations are licensed under the identical terms.

\begin{tabular}{|l|l|}
\hline \multicolumn{3}{|c|}{ Access this article online } \\
\hline Quick Response Code: & Website: \\
\hline & www.jps.org \\
\cline { 2 - 3 } & DOI: \\
\hline
\end{tabular}

How to cite this article: Twoon M, Hallam MJ. Anticoagulation therapy and hand surgery: Do we worry too much?. Indian J Plast Surg 2015;48:326-7. 